\title{
Editorial: Energy Economics and Energy Finance in Developing and Emerging Countries
}

\author{
Hooi Hooi Lean ${ }^{1 *}$ and Chien-Chiang Lee ${ }^{2}$ \\ ${ }^{1}$ Economics Program, School of Social Sciences, Universiti Sains Malaysia, Penang, Malaysia, ${ }^{2}$ School of Economics and \\ Management, Nanchang University, Nanchang, China
}

Keywords: energy economics, energy finance, emerging countries, developing countries, empirical and policy

Editorial on the Research Topic

Energy Economics and Energy Finance in Developing and Emerging Countries

The move towards low carbon emissions has exposed developing and emerging economies to various energy and economic sustainability challenges-these include high energy prices and costs volatilities, high dependence on imported energy, the lack of sustainable financial supports, technologies and skilled labors, etc. Indeed, this structural change in the economy may cause fossil fuels to become increasingly costly and difficult to operate, thus resulting in a lower growth in fossil fuel energy production and demand. High volatility and uncertainty in world energy prices may add additional pressure to increasing production costs and suppressing households' purchasing power. In this emerging framework, investments in renewable and clean energy production, and energy efficient products and technologies need significant input and support from developed countries. Developing and emerging economies need to figure out better and more sustainable financing schemes for advocating clean-energy investments and new product developments.

This Research Topic collects articles that examined the theory, several empirical studies and policy related issues of energy economics and energy finance within developing and emerging economies. It received very positive and supportive responses from various stakeholders globally. Since it began in 2019, there were 26,195 total views; 21,699 article views; 2,556 article downloads; 1,940 topic views as at 5, January 2022. Demographically, the top five countries of views are the United States of America with 4,284, China with 2,970, India with 2,127, Germany with 2,027, and the United Kingdom with 1,030. Eight articles that were published within this Research Topic can be found at: https://www.frontiersin.org/research-topics/11071.

The first paper on this issue was by Apergis et al. It is about the convergence of carbon dioxide emission intensity for a specific geographical area, namely, the Central American region. Understanding such properties is of crucial interest for energy and environmental economists. From a policy-making perspective, it provides knowledge on the effectiveness of mitigation strategies. The club convergence approach allows them to detect the possibility of multiple convergence clubs. With the consideration of the convergence behavior of energy intensity and the carbonization index, the results provide insights into the implementation of natural resource management and environmental protection policies.

The second paper on this issue by Ali et al. explores the determinants of carbon dioxide emissions in Nigeria. Besides the traditional observation of the Environmental Kuznets Curve (EKC) hypothesis, they also highlight the importance of agricultural innovation and biocapacity in affecting carbon emissions. The results show that the former factor would cause emissions to rise, while the latter would reduce it. Implications from their analysis are important to policymakers to develop ecosystem management and restoration and combat climate change and its devastating impacts.

Lee $C-C$ Economics and Energy Finance in Developing and Emerging Countries.

Front. Energy Res. 10:814273. doi: 10.3389/fenrg.2022.814273 
The third paper is by Bertrand et al. The authors provide a practical guide of wind-energy production modeling using the Weibull distribution in the Southern Region of Cameroon. This subject is important because over the decades, the development of renewable energy has become one of the solutions to achieving sustainable development and fighting against climate change. Four parameter determination methods, i.e., the graphical method, the empirical method, the method of factor energy, and the moment method, are used and compared. They show that the empirical method presented a better performance than the other techniques. The results can help policymakers to evaluate possible projects for electricity production using the wind thus contributing to the sustainable development of the local economy.

The fourth paper on this issue by Aarakit et al. is about the market potential of solar photovoltaic systems in Sub-Saharan Africa. This study relatively succeeds at estimating the market potential for alternative electricity sources using electricity demand and supply-side gaps. In their analysis, the combination of supply-side and demand-side gaps constitute total electricity access deficit in households which is considered a market potential for alternative electricity generating sources. Insights from their analysis provide strong evidence for solar energy generating companies in making effective and efficient market segmentation and for policymakers in designing appropriate access to the market for solar energy and electricity generation producers; and attractive tax subsidies to the right stakeholders.

Tucho and Kumsa review the "Challenges of Achieving Sustainable Development Goal 7 From the Perspectives of Access to Modern Cooking Energy in Developing Countries." The challenges are critical in Sub-Saharan Africa where the majority of the population does not have access to modern cooking energy services. This low attainment of such a basic utility could be due to the interrelated deeply-rooted socio-economic, cultural, and technical factors within these communities.

"Energy and Financial Market Interactions" is authored by Shaiban et al.. The paper investigates how oil price shocks affected the performance of certain country-specific banking industries. They find that oil price rises have a negative impact on equity in banking indices in the emerging economics except for the banking equity in Mexico. They suggest that international banking portfolio investors should consider hedging oil price risks.

In "Environmental Regulation for Transfer of PollutionIntensive Industries: Evidence from Chinese Provinces," $\mathrm{Li}$ et al. finds that increases of formal environmental regulation promotes the transfer out of pollution-intensive industries. The paper then puts forward their policy suggestions including the utilization of clean energy-saving technologies in the industrial sector to realize the delicately balanced coordinated development of environmental protection and economic growth.

The last article "Are the Responses of Sectoral Energy Imports Asymmetric to Exchange Rate Volatilities in Pakistan? Evidence from Recent Foreign Exchange Regime" is authored by Abdul Saqib et al. They examine the impacts of the Pakistani Rupee's (currency's) volatility on monthly energy imports. Overall, the empirical assessment reveals that the foreign exchange volatility effect is sectoral, specific and asymmetric in Pakistan. It offers new insights to the policymakers to re-strategize the energy policy and for refining the imports substitution plan.

In summary, these papers collectively show how the developing and emerging countries deal with the issues within the energy-economics nexus and the finance issues which are examined empirically with the relevant data obtained within the respective country/region. Development and implementation of clean energy saving technologies and environment protection toward sustainable development are the major concerns not only in these parts of the world but is increasingly a major global concern.

\section{AUTHOR CONTRIBUTIONS}

All authors listed have made a substantial, direct, and intellectual contribution to the work and approved it for publication.

Conflict of Interest: The authors declare that the research was conducted in the absence of any commercial or financial relationships that could be construed as a potential conflict of interest.

Publisher's Note: All claims expressed in this article are solely those of the authors and do not necessarily represent those of their affiliated organizations, or those of the publisher, the editors and the reviewers. Any product that may be evaluated in this article, or claim that may be made by its manufacturer, is not guaranteed or endorsed by the publisher.

Copyright (c) 2022 Lean and Lee. This is an open-access article distributed under the terms of the Creative Commons Attribution License (CC BY). The use, distribution or reproduction in other forums is permitted, provided the original author(s) and the copyright owner(s) are credited and that the original publication in this journal is cited, in accordance with accepted academic practice. No use, distribution or reproduction is permitted which does not comply with these terms. 